\title{
Small-Particle Solar Receiver for High-Temperature Brayton Power Cycles
}

\section{SAN DIEGO STATE UNIVERSITY}

$\begin{array}{ll}\text { PROGRAM: } & \text { SunShot CSP R\&D } 2012 \\ \text { TOPIC: } & \text { Advanced Receivers } \\ \text { LOCATION: } & \text { San Diego, California }\end{array}$

AWARD

AMOUNT:

Up to $\$ 3.8$ million

PROJECT TERM: $\quad 2012-2016$

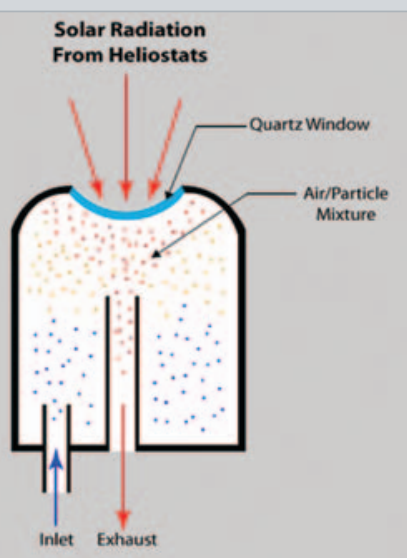

This conceptual schematic shows a small particle solar receiver. Concentrated radiation from the heliostat field is absorbed directly in a gas-particle suspension rather than on the receiver walls. The carbon nanoparticles oxidize as they transit the receiver, resulting in a clear gas stream exiting toward the turbine. Illustration from San Diego State University

\section{CONTACTS}

\section{Project Leader:}

Dr. Fletcher Miller

fletcher.miller@sdsu.edu

\section{Partnering Organizations:}

- L-3 Integrated Optical Systems

- Pratt \& Whitney Rocketdyne

- Solar Thermal Consulting

- Solar Turbines Incorporated

\section{MOTIVATION}

Central receiver power plants that incorporate a gas-based Brayton cycle rather than a steam-based Rankine cycle can increase plant efficiency and eliminate the need for cooling water. In addition, the concept of a small-particle receiver offers further advantages over competing gas-cooled receiver designs. Based on previous $30-\mathrm{kW}$ tests and subsequent numerical modeling, the Small Particle Heat Exchange Receiver (SPHER) represents a gas-cooled central receiver capable of producing pressurized air in excess of $1,000^{\circ} \mathrm{C}$.

\section{PROJECT DESCRIPTION}

The objective of this project is to validate, through on-sun testing, the viability of the SPHER concept. This concept uses carbon nanoparticles dispersed in air to absorb highly concentrated solar flux inside a windowed pressure vessel, rather than on a solid surface as in most other receivers. The research team is demonstrating the use of a large, pressurized window, particle generator, and unique receiver configuration to produce a low-cost, high-efficiency, reliable, high-temperature receiver that is capable of powering a gas turbine for electricity production.

\section{IMPACT}

If successful, this project team would build the first largescale, pressurized, high-temperature, gas-cooled solar receiver capable of being deployed commercially. While the proposed use for this receiver is to drive a gas turbine, such a receiver could also be used to produce high-temperature process heat and for solar processing of fuels and chemicals.

For more information, visit the project page at: www.solar.energy.gov/sunshot/csp_sunshotrnd_sdsu.html. 